\title{
An integrated assessment of options for rural wastewater management in Austria
}

\author{
M. Starkl*, M. Ornetzeder ${ }^{\star *}$, E. Binner*, P. Holubar ${ }^{\star \star *}$, M. Pollak ${ }^{\star \star \star *}$, M. Dorninger ${ }^{\star \star \star * *}$, \\ F. Mascher ${ }^{\star \star \star \star \star *}$, M. Fuerhacker ${ }^{\star}$ and R. Haberl* \\ *Department for Water-Atmosphere-Environment, University of Natural Resources and Applied Life \\ Sciences, Vienna, Austria, Muthgasse 18, 1190 Vienna, Austria (E-mail: markus.starkl@boku.ac.at) \\ ${ }^{\star *}$ Centre for Social Innovation (now: Austrian Academy of Sciences - ITA), Vienna, Austria \\ ***Department for Biotechnology, University of Natural Resources and Applied Life Sciences, Vienna, Austria \\ ****wpa consulting engineers, Vienna, Austria \\ ${ }^{\star \star \star \star \star}$ Department of Sustainable Agricultural Systems, University of Natural Resources and Applied Life \\ Sciences, Vienna, Austria

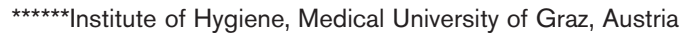

\begin{abstract}
This paper reports a recently finished, interdisciplinary project on rural wastewater management in Austria. The objective of the project was to study alternative wastewater management options based on separation of the wastewater into its constituent parts, and to compare them with conventional ones. Thereby, a feasibility study of both conventional and alternative options for wastewater management in six model regions was carried out. Life cycle costs and social acceptance were analysed by using a case study-based assessment approach. However, hygienic and environmental risks were evaluated on a more general level. In order to complement the findings, a survey on urine separation system users in the Solar City of Linz was conducted. Based on these assessments and empirical findings, the paper concludes that options using a full separation of all wastewater fractions should be considered with care. Options based on a separation of only grey water and black water or in the liquid/solid phase can offer ecological and financial advantages over conventional options. Further, options combining wastewater management and regional biogas plants were identified as an interesting solution. However, legal constraints restrict this option currently.
\end{abstract}

Keywords Assessment; case studies; integrated assessment; options; risks; wastewater management

\section{Introduction}

In Austria, about $10-15 \%$ of the population still does not have an adequate wastewater management system. For instance, in the province of Lower Austria about 200,000 inhabitants are still connected to cesspits or simple mechanical treatment systems. Furnishing these rural communities with conventional, centralised technologies would create high costs. As urban water management is subsidised by the federal government, these costs are of great political concern. For instance, the Austrian Kommunalkredit AG (which manages the funds for urban water management on behalf of the Ministry for Agriculture, Forestry, Environment and Water Management) spends about 250,000 EUR/ year on subsidies for urban water management. Further, the highest subsidies are available for areas with a low connection density (the top funding rate is currently $70 \%$ of investment costs). Moreover, in recent years, the traditional combined flow options for wastewater management have been criticised by several authors (e.g. Larsen and Gujer, 1996; Otterpohl et al., 1999; Wilderer and Schreff, 2000). These authors, among many others, argue that the traditional method of sanitation does not reuse the nutrients which wastewater contains, and that the invested capital is tied up in infrastructure (sewerage

doi: $10.2166 /$ wst.2007.562 
system, pumping stations, wastewater treatment plants (WWTP)), which is inflexible and designed for the maximum theoretical wastewater flow.

In order to overcome these weaknesses, alternative technologies based on the separation of the wastewater into its constituent parts, grey water and black water, where black water can further be separated into yellow water (urine) and brown water (faeces and flushing water), are proposed.

Traditionally, farmers in several Austrian provinces prefer to apply their domestic wastewater together with manure on their agricultural lands. However, inhabitants of rural communities who are not farmers need to collect their wastewater in tight tanks (septic tanks) and to arrange transport to a wastewater treatment plant, which causes high costs. Hence, the question arises, if synergies between agriculture and wastewater management would allow for more efficient forms of wastewater management for both farmers and non-farmers. Further, a better cooperation between solid waste management and wastewater management may offer advantages. For instance, composting of biogenic material and use of the compost in agriculture is a frequently applied practice in rural communities. This paper reports about the results of the project "Applied strategies towards sustainable sanitation (SUS-SAN)", which was commissioned by the Ministry for Agriculture, Forestry, Environment and Water Management, and seven out of nine Austrian provinces (Starkl et al., 2005). This project analysed potential synergies between wastewater management on the one hand, and agriculture and solid waste management on the other.

\section{Goal and methodological approach}

The philosophy of the project is illustrated in Figure 1. It is assumed that centralised options are the first choice to be looked at (as at the time these systems were built, their design loads were usually based on the later connection of all rural areas). Only if an economic connection to an existing centralised system is not possible (and legally not mandatory), do alternative options need to be considered. Thereby, SUS-SAN looked at options which separate the wastewater into its constituent parts, grey water and black water, where black water can further be separated into yellow water (urine) and brown water (faeces and flushing water). The idea is that these fractions can locally be treated and/or recycled more cost efficiently. However, such a concept is only acceptable if the problems of wastewater management are not shifted to agriculture or solid waste management, but that real synergies can be used between these sectors. A prerequisite for using synergies with agriculture and solid waste management is that the concentrated wastewater fractions (black water, brown water, urine) on the one hand cause benefits, and on the other, do not cause harm, to the cooperating sectors. The benefit is assessed in economic terms. Harm could be caused by the pollutants in the fractions to be recycled.

Based on selected case studies, an integrated assessment of both conventional and alternative options was carried out, following a more policy-oriented approach as outlined, e.g., in Starkl et al. (2005). The integrated assessment covered economic, social, hygienic and environmental risk-based aspects. Further, an analysis of the relevant legal material was carried out in order to assess any legal constraints in applying alternative options. The assessment of costs was carried out as a part of the feasibility study for the case study areas, and the social assessments were conducted with the inhabitants in the case study communities. The assessment of hygienic and environmental risks was then based on more general considerations. Hygienic risks were assessed in a qualitative way for the conceptual wastewater management systems, taking into account measures for 


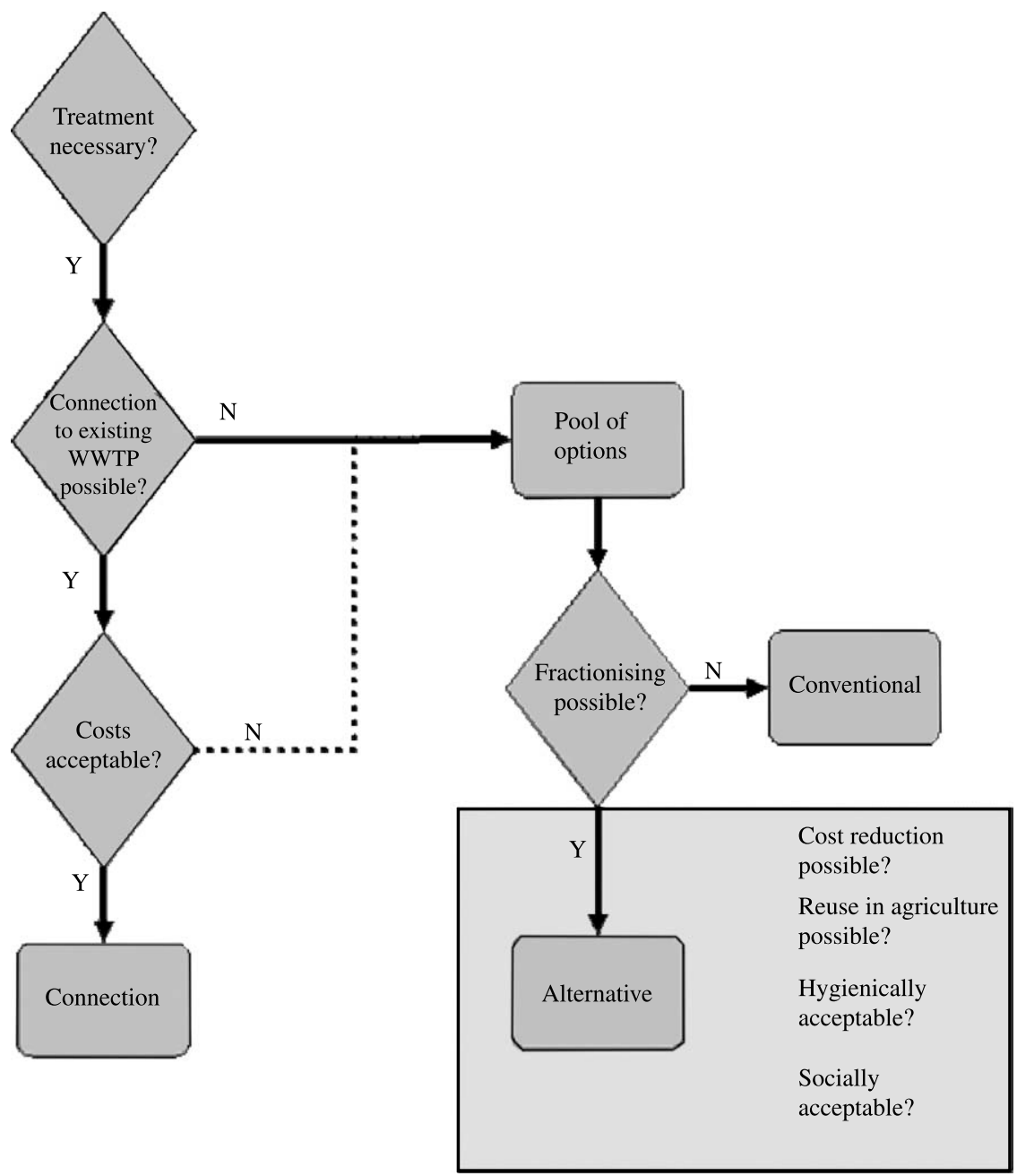

Figure 1 Decision tree for applying alternative concepts

composting systems). As a major environmental risk for applying urine in agriculture, the wash-out of micro-pollutants into the groundwater was considered. Based on a "worst case" and a "realistic case", a risk assessment was carried out.

\section{Pool of options and case studies}

The analysis of potential synergies between wastewater management on the one hand, and agriculture and solid waste management on the other, resulted in the following additional options for wastewater management.

\section{Treatment of fractions}

- Co-treatment of black water in an existing regional biogas plant. It is assumed that the small quantities of domestic black water generated in rural communities have no adverse impact on a regional biogas plant. In the case studies such regional biogas plants were identified and costs of such a co-treatment were calculated.

- Separating the wastewater into solid and liquid phases, such as the STEP/STEG system of the US-based company Orenco (this is a system where only the filtered effluent of a septic tank is transported through a pipe to a treatment plant, and 
the remaining sludge needs to be removed once every few years), or alternatively a "separator system" as e.g. produced by the Swedish-based company Aquatron (this has the shape of a cyclone in which the solid phase is separated from the liquid phase through gravity).

- Treatment of the black water in an aerobic baffled tank reactor with a subsequent soil filter.

- Collection of the brown water in a "Rottesack" and composting of the resulting substrate.

- Application of composting toilets.

- Collection of dewatered wastewater and composting.

For composting two systems were considered: in-house (or in garden) composting carried out by the house owner, and external composting in a professional composting plant.

Recycling of the fractions

- Treatment/co-treatment in a biogas plant and using the resulting substrate in agriculture

- Treatment/co-treatment in a composting plant (in-house composting or external composting) and using the compost in agriculture.

- Direct application of the wastewater or its fractions in agriculture.

- Direct application of urine in agriculture.

- Mixing of urine with manure and application in agriculture.

- Collection of grey water and using it for diluting manure or treatment in a constructed wetland.

The requirements for treatment of wastewater in the case studies are based on the Austrian Emission Standards for communal wastewater. The emission standards are more stringent than the official European Union standards, and demand effluent values of $25 \mathrm{mg}$ BOD plus nitrification $\left(10 \mathrm{mg} / \mathrm{L} \mathrm{NH}_{4}\right)$ for treatment plants below 500 PE. This case is referred to in the following part as Case 1. In addition, for seasonally dry water courses, higher emission standards have to be followed. However, there are no prescribed standards for this. For each case, the responsible local competent authority prescribes an appropriate standard, based on an analysis of the concrete situation. This case is referred to as Case 2.

In order to evaluate the costs and social acceptance of the different options, six case studies in three Austrian provinces were selected. A case study was a smaller area of a rural municipality (existing communities ranging from 10 to $87 \mathrm{PE}$ ), which up to now have only had cesspits (which are not state of the art according to the legislation) and hence need to improve their existing system. A conceptual feasibility study as well as a dynamic life cost calculation of all available options was carried out. Then, the results were discussed with the future users and a social analysis was carried out (this part was only carried out in three of the six case studies). Together with the conventional options, the project basically distinguished between two groups of options.

Group A (conventional options) comprises three systems: centralised (A1) or decentralised (A2) treatment plants and cesspits (A3). The alternative options (Group B) are further classified according to the separated wastewater fractions: black and grey water (B1), only urine (B2), all three fractions grey, yellow and brown water (B3) or only a separation into the solid and liquid phase of the wastewater (B4). In addition, for the above-mentioned Case 2, based on informal discussion with the responsible local competent authority, it was assumed that treating the full wastewater (Group A1) or the mixture of black and grey water (Group B2), with either a technical-biological treatment plant followed by a constructed wetland or sand filter, or a membrane bioreactor (MBR), 
would allow the effluent to comply with Case 2. For the treatment of the other fractions assumptions had to be made, owing to a lack of experience with such plants. For grey water purification, constructed wetlands and trickling filters were considered. As it contains less than $50 \%$ of the BOD, $\mathrm{P}$ and $\mathrm{N}$, it was assumed that the treatment plants can be designed $50 \%$ smaller than for conventional wastewater treatment. Wastewater without urine contains $80 \%$ less nitrogen; therefore, cheaper anaerobic treatment plants could be applied. An anaerobic baffled reactor (ABR) followed by a soil filter was considered. For Case 2 it was assumed that a conventional treatment plant followed by a sand filter (instead of a more expensive constructed wetland as above) is sufficient. Some options generate coarsely filtrated wastewater which is then being mixed with the grey water. Here it was assumed that the new mixture needs a treatment plant which can be designed about two-fifths smaller than a conventional wastewater treatment plant.

\section{Results and discussion}

\section{Cost assessment}

The considered costs encompass investment and reinvestment costs, costs for operation and maintenance, as well as costs for transport and disposal of final substrates (e.g. sludge, compost, etc.). The cost calculation used the net present value method, following the German LAWA guidelines (LAWA 2005). The time frame is 50 years.

In order to assess the robustness of the results against cost uncertainties, in addition a Monte Carlo simulation of the costs was carried out. Based on experience with cost uncertainties from real projects, this simulation used four influencing factors:

$q$ : costs of sewers and pumping stations;

$r$ : costs of treatment plants and storage tanks;

$s$ : costs of transport;

$t$ : costs for disposal of sludge in wastewater treatment plants.

These factors have been set according to actual experiences of cost uncertainties in practice at the following values: $q$ : $0.5-1.5 ; r: 0.75-1.25 ; s: 0.95-1.05 ; t: 0.5-1.5$. Then, 1,000 simulations were carried out which showed if the ranking of the options would change within these variations.

The cost calculations in all case studies show advantages for the alternative options. On average for all case studies, the cheapest alternative option is about $25 \%$ cheaper than the cheapest conventional option. In particular, the following alternative options can reduce costs. Installation of urine sorting toilets reduces the flush water considerably which results in less cost for emptying the septic tanks (this applies for Group A2 and B1). Application of a STEG/STEP system can reduce the costs for the sewer considerably, but this depends on regional characteristics (e.g. in one Austrian province the standardised unit costs for sewers are almost independent from the sewer size up to $200 \mathrm{~mm}$ ). Concepts based on tight cesspits out of Group A2 (which were often among the preferred options), are - if transport of the sewerage is foreseen to a WWTP - considerably more expensive. This option is only competitive if local farmers directly use the sewage sludge in agriculture (which is allowed up to a certain quantity in some provinces). Options based on upgrading of existing cesspits or septic tanks to a small-scale sequencing batch reactor or membrane bioreactor (producers offer special packages for such an upgrade) also proved to be not very cost-effective for the considered case studies.

The separation of urine (Group B2) or the separation of all wastewater fractions (Group B3) did not show any economic advantages. Only the application of composting toilets with garden composting (an option within Group B3) was an economically 
advantageous option in one case study for a single house (where the direct application of raw wastewater on agricultural soils was not permissible).

\section{Social analysis}

Social acceptance is of major importance for the diffusion and use of new technological options. According to Endruweit and Trommsdorff (2002) social acceptance is a positive reaction regarding the implementation of technical innovations. The evaluation of social acceptance of new wastewater management options within the project was designed to produce relevant information for both, the further technological development in this field as well as to support the decision-making processes in the case study municipalities. In order to get qualitative information on several new technological options we decided to carry out focus group discussions on location with concerned residents. Based on the "pool of options" for each case study the most appropriate options have been selected and presented to focus groups. All directly concerned homeowners have been invited by the municipalities to attend the presentation. The focus groups in our cases were comprised of 12 to 15 participants, which means that most of the concerned population was involved. Each focus group discussion was organised in a similar way. It started with general information on the research project, followed by a presentation of possible wastewater options for the planning area. After these presentations by project staff members the audience could raise questions that were followed by discussions on the presented technical options. Finally, a concluding assessment of options was gathered by means of a written questionnaire. In order to complement and verify the results of these focus group discussions, a survey on user experiences in a new development area of the city of Linz, where about 90 flats are equipped with urine sorting toilets and the tenants had about 1 year operational experience with such systems, was carried out.

Focus group members in all three cases have been very interested in alternative wastewater technology. Most of the presented alternative options are ranked much higher than centralized sewer systems. On a more general level, we can conclude that new options are attractive to the concerned population, if they are similar to well-known technology (e.g. septic tank solutions are similar to existing cesspits); they are positively described by experts and major problems did not arise during the discussion (which leads to methodical problems); and the implementation is supported by subsidies and scientifically monitored.

Technological options which demand behavioural changes - in our case urine-separating toilets or compost toilets - do not find much favour. The acceptance of these two options is rather small, even if they result in lower overall costs. Compost toilets have been on the market for many years but are hardly in use. With regard to this situation evaluation knowledge is also very limited. The results of focus group discussions in our project reveal a similar picture. Compost toilets are not an option. Participants argued that this solution needs additional space in the cellar (which often is not available), that there is a much higher maintenance effort (compared with conventional toilets), and finally, people think that compost toilets would cause a bad smell. Only very few participants would be interested in using self-produced compost in their own garden.

Urine-separating toilets are also perceived as a problematic solution. Focus group participants had been confronted with this technical option for the first time. After discussing various aspects of this technology nobody was willing to consider urine-separating toilets as a realistic option. Most important reasons against urine separation concern expected costs and additional constructional effort. Further, participants are in doubt about the assumed positive environmental effects. Results from our written survey on users of urine-separating toilets show a similar picture. The results of these studies were 
then verified with a social analysis of tenants of the Solar City in Linz, Austria, where around 90 flats in a new development area are furnished with urine-sorting toilets. Based on a year-long use-period every second user would prefer to change to a conventional toilet, if it was possible. Most users report cleaning problems and less comfort compared with conventional systems. Even satisfied users agree with this. Although most users are dissatisfied with their toilet model many of the respondents think that changes of the toilet design could help to improve the comfort and user friendliness. Our results also show that social acceptance of separating toilets is closely linked to the plausibility of the overall system. Users who believe that urine separation is an environmentally friendly measure are more likely to be satisfied with the toilet too. Another drawback is that compared with conventional toilets users of urine-separating toilets need to flush more often to clean the toilet, which leads to considerably higher use of water than expected.

The separation of grey and black water in the houses was recommended and discussed in two municipalities. This option was very attractive for future users in both cases (ranked first and second, respectively). Even participants with an agricultural background - a highly sceptical social group in our cases - took this option into consideration. The positive image of this option could be explained by three main reasons: first of all, this option is one of the most cost-effective solutions in the long term; second, this option could be easily combined with positively perceived constructed wetlands; and the third reason is that this kind of separation is partly in use in the area already (participants know users of this solution) and apparently it works quite well.

\section{Recycling of urine in agriculture}

Another question discussed in the project was: how relevant is the contribution of urineseparating systems to solve nutrient cycles in agriculture? This question was analysed from the perspective that agriculture should not be "misused" for disposal of any substrates, as mentioned earlier. In order to reach a real "recycling", two aspects need to be ensured: first, the substrate should have a benefit for agriculture and at the same time cause no harm to it. In order to answer if recycling of urine gives a benefit, a study on nutrient balances was carried out for the province of Lower Austria. It shows that if all households that do not yet have an adequate wastewater management system (about $180,000)$ were to be equipped with a urine-sorting system, only about $1.68 \%$ of the total used mineral fertilisers for $\mathrm{N}$ could be substituted. For $\mathrm{P}\left(\mathrm{P}_{2} \mathrm{O}_{5}\right)$ and $\mathrm{K}\left(\mathrm{K}_{2} \mathrm{O}\right)$ it would be even less: 0.9 and $1.1 \%$, respectively. First, this study has shown that on the one hand even large-scale implementation of urine-sorting systems would only provide marginal quantities of nutrients compared with the commercial fertilisers used; second, many areas in Austria have too many nutrients available; and third, the benefits of urine would only be marginal (around 5 EUR commercial value of $1 \mathrm{~m}^{3}$ of urine based on its nutrient composition). However, on the other hand, there would be no problem in applying the urine in agriculture (if appropriate measures for risk management are taken and it would be legally possible) as the quantities are very low.

Further, closing the nutrient cycle is often cited as an important benefit of systems allowing for a use of urine as a fertiliser. In the course of the project SUS-SAN, for two regions (out of four) in the province of Lower Austria, a more detailed nutrient balance was carried out. The aim of this exercise was to identify process chains in agriculture in order to allow a system-based connection of different agro-based technologies. Thereby, different agricultural development scenarios (e.g. increasing growing of energy plants, reducing green land, restriction of manure application, etc.) were considered (based on e.g. Buchgraber, 2004). As a result of this, the Seaborne process (www.seaborne.de), which can process sewage, manure and biogenic material, was identified as an interesting 
option. This process is producing a substrate which can be used as fertiliser, biogas, current, and other substrates which can be recycled.

\section{Environmental risks}

Owing to space limitations, the method and results of the risk assessment will be published elsewhere. Basically, a risk to the groundwater for wash out of urine from the soil was identified. Then, in view of hygienic risks, only in-garden composting (owing to a lack of monitoring of the sensitive composting process) and direct application of sewage or its fractions (apart from urine) on agricultural soils were considered to be unacceptable. All other options would be allowed for cost-effective risk management strategies (e.g. 6-month storage for urine). The costs for such measures were considered in the cost assessments.

\section{Conclusions}

The results of this project are based on the real constraints in Austria, and in particular on the results of the case study-based assessments. From the pool of conventional options (A), the case studies showed that both centralised (A1) and decentralised (A2) conventional options could be optimal solutions, depending on the local constraints. This is an interesting result insofar, as often in political discussions, centralised solutions are considered to be a priori inferior to decentralised solutions. Cesspits (A3), even if often among the most preferred options within communities, clearly are economically not competitive (if real O\&M costs are considered). Taking into account all aspects, out of the pool of alternative options, those of Group B1 without using a urine-sorting toilet and the STEG/STEP system out of Group B4 can be recommended. In particular, options from Group B1 have further potential for cost reduction, as the constructed wetlands used for treating the grey water could be designed in a cheaper way (e.g. by reducing the required area to about $1 \mathrm{~m}^{2} / \mathrm{PE}$ and using cheaper substrate). Additional research is necessary to demonstrate this. Although the use of composting toilets with in-garden composting could be cost-effective for households in remote areas, such solutions are hardly acceptable from a hygiene point of view (owing to a lack of monitoring of the sensitive composting process) and highly problematic regarding social acceptance. If such concepts were to be implemented, special scrutiny would need to be given to their approval and the monitoring process.

Another interesting option would be the direct processing of black water or brown water in a regional biogas plant. From a technical perspective up to $10 \%$ of brown water or black water would cause no problem to a regional biogas plant, but this option is not feasible within the existing regulations. Changing the legal situation here could have a considerable impact on wastewater management in rural areas. As a side result, the Seaborne process was identified as an interesting option. It would allow a system combining processing of sewage, manure and biogenic material. For the wastewater management sector this would mean that all existing infrastructure can be kept and that no separation is necessary, whereas a full potential of recycling of nutrients could be utilised. However, further research is needed to demonstrate this process.

Whatever option is selected, an important point is to ensure a successful operation for its full life time (which is up to 50 years). Taking into account the users' preferences and in particular their ability to operate the system (in the case that the operation is community based) seems to be key to a successful operation, in particular as the decision for a wastewater management system is essentially a collective decision for all 


\section{Acknowledgements}

The authors thank the Austrian Federal Ministry for Agriculture, Forestry, Environment and Water Management and the Provincial Governments for funding the project reported.

\section{References}

Buchgraber, K. (2004). Energetisch und stofflich nutzbare Biomasse aus dem österreichischen Grünland (Energetically and materially usable biomass from Austrian green land). The Research and Education Centre for Agriculture, 10th Alpine Expert Forum, Raumberg-Gumpenstein, 1-5.

Endruweit, G. and Trommsdorff, G. (eds) (2002). Wörterbuch der Soziologie (Dictionary of Sociology), Stuttgart, 2002.

Larsen, T.A. and Gujer, W. (1996). Separate management of anthropogenic nutrient solutions (human urine). Wat. Sci. Tech., 34(3-4), 87-94.

LAWA (2005). Leitlinien zur Durchführung dynamischer Kostenvergleichsrechnungen (guidelines for dynamic cost comparisons). Länderarbeitsgemeinschaft Wasser, Germany.

Otterpohl, R., Albold, A. and Oldenburg, M. (1999). Source control in urban sanitation and waste management: ten systems with reuse of resources. Wat. Sci. Tech., 39(5), 153-160.

Starkl, M., Brunner, N., Grasser, U., Moog, O., Stagl, S., Kärrman, E., Wimmer, J., Szewieczek, R. and Haberl, R. (2005). Analysis and evaluation of methodologies to assess technical urban water systems. Wat. Sci. Tech., 52(9), 43-51.

Starkl, M., Binner, E., Fürhacker, M., Holubar, P., Koeck, S., Lenz, K., Mascher, F., Ornetzeder, M., Pollak, M. and Haverl, R. (2005). Nachhaltige Strategien der Abwasserentsorgung im ländlichen Raum (Sustainable strategies for wastewater management in rural areas) - Final Report. Austrian Ministry of Agriculture, Forestry, Water Management and Environment, Vienna, 2005.

Wilderer, P.A. and Schreff, D. (2000). Decentralized and centralized wastewater management. A challenge for technology developers. Wat. Sci. Tech., 41(1), 1-8. 